\title{
The influence of Calcium doping on structural and electrical properties of ferroelectric Lead Titanate ceramic
}

\author{
Nagarbawadi M. A. , Jangade P. S. , Bagwan S. T. \\ ${ }^{a}$ Department of Physics, Poona College, Pune-411001(MS), INDIA. \\ ${ }^{b}$ Department of Physics, G. H. Raisoni College of Engg. and Management, Pune-412207(MS), INDIA. \\ ${ }^{c}$ Department of Physics, Abeda Inamdar Senior College, Pune-411001(MS), INDIA.
}

\begin{abstract}
A series of Lead Titanate ceramic with various concentration of Calcium has been prepared by solid state reaction method, and some of their physical properties and structural characteristics have been studied. The incorporation of small amount of Calcium results in considerable changes in the dc electrical conductivity and the temperature of the ferroelectric phase transition. Lead Titanate (PT) is a well known ferroelectric with high curie point and low dielectric thus constant making it an attractive proportion for various applications. The synthesis of Calcium modified $\mathrm{PbTiO}_{3}$ was carried using solid state reaction method. Stoichiometric amount of high purity $\mathrm{CaO}$ was used as a dopant in different proportion and the final product was in powder form. The $X$-ray diffraction pattern was taken for pure and $\mathrm{CaO}$ modified Lead Titanate. The SEM of the sample was done on JEOL 6360A Analytical Scanning Electron Microscope. There is an observable change in grain size with different molar concentration of Calcium oxide. The DC conductivity of the sample was carried out using two probe method over a range of temperature covering their transition temperature.
\end{abstract}

Keywords: Curie temperature, $\mathrm{CaO}, \mathrm{DC}$ conductivity, $\mathrm{PbTiO}_{3}, \mathrm{SEM}$,

\section{Introduction}

Materials exerting a giant dielectric constant have gained a great deal of attention. Since the discovery of ferroelectricity in a single crystal of Rochelle salt in 1921 [1], there have been many attempts to find new materials that possess a high dielectric constant (k). The area of interest of the present work is the electronic ceramics, which are highly specialized class of materials. Their properties are predominantly controlled by their composition in addition to processing conditions \& complexities of shape [2]. Various types of electronic ceramics are insulators, ferrites, capacitors, PTC materials, ferroelectrics, pyroelectrics, piezoelectrics, electrooptic materials etc. The ferroelectric materials possess the spontaneous polarization even in the absence of an electric field and the direction of spontaneous polarization can be changed by an applied electric field [3-5]. Lead Titanate is a ferroelectric material having a structure similar to $\mathrm{BaTiO}_{3}$ with a high Curie point $\left(490^{\circ} \mathrm{C}\right)$. It has perovskite structure and exists in two crystal structures Cubic and Tetragonal [6-9]. Pure lead titanate has cracks and fractures while fabrication and these strains can be removed by adding various dopants such as $\mathrm{Ca}$, etc. These are well known materials due to their phase transitions which may affect their physical, chemical, electrical properties. An interesting feature of perovskite structure is that they are very simple but shows many variations with phase transitions between different structures. The stability of perovskite structure is given by tolerance factor $(\tau)[10,11]$ and is calculated by

$$
\tau=\left(\mathrm{R}_{\mathrm{A}}+\mathrm{R}_{\mathrm{X}}\right) /\left[\sqrt{ } 2\left(\mathrm{R}_{\mathrm{B}}+\mathrm{R}_{\mathrm{X}}\right)\right]
$$

Where $\mathrm{R}_{\mathrm{A}}, \mathrm{R}_{\mathrm{B}}$ \& $\mathrm{R}_{\mathrm{X}}$ are ionic radii for $\mathrm{A}$ and $\mathrm{B}$ cations \& $\mathrm{X}$ anion. The tolerance factor is a useful structure guide. Present work deals with the structural and electrical properties of Lead Titanate (PT) sample with additives. The modification of this sample was carried out by adding Calcium in proportion of 5 to $25 \mathrm{~mol} \%$. The properties like structural analysis, grain size determination and dc conductivity were studied for the pure Lead Titanate sample and for the Calcium modified Lead Titanate (PCT).

\section{Synthesis of pure Lead Titanate $\left[\mathrm{PbTiO}_{3}\right]$ and Calcium modified Lead Titanate (PCT)}

The starting materials were commercially available Lead Carbonate, $\mathrm{PbCO}_{3}(\mathrm{GR})$ and Titanium dioxide, $\mathrm{TiO}_{2}$ (GR) with $99 \%$ purity. $\mathrm{PbTiO}_{3}$ powder was synthesized by the solid state reaction of thoroughly ground mixtures of $\mathrm{PbCO}_{3}$ and $\mathrm{TiO}_{2}$ powders that were milled in an agate mortar in the required stoichiometric ratio. The milling operation was carried out for $5 \mathrm{hrs}$. After milling, the powder sample was calcinated at $900^{\circ} \mathrm{C}$ for 5hours. The reaction for the $\mathrm{PbTiO}_{3}$ formation is

$$
\mathrm{PbCO}_{3}+\mathrm{TiO}_{2} \rightarrow \mathrm{PbTiO}_{3}+\mathrm{CO}_{2} \uparrow
$$


Stoichiometric amounts of high purity Calcium oxide, $\mathrm{CaO}$ (all over $\sim 99.9 \%$ purity) were carefully weighed and added in a proportion of $5,10,15,20,25 \mathrm{~mol} \%$ with synthesized Lead Titanate $\left(\mathrm{PbTiO}_{3}\right)$ powder. This powder mixture was mixed in an agate mortar for $2 \mathrm{hrs}$. In order to reduce the impurities and obtain homogeneity of the final compound the samples were sintered in silica crucible at $750^{\circ} \mathrm{C}$ for $5 \mathrm{hrs}$ [12]. The sintered material was cooled, crushed \& once again ground thoroughly by adding organic binder. This sintered material was pressed by applying a pressure of $70 \mathrm{~kg} / \mathrm{m}^{2}$ for 5 minutes using hydraulic press. Pellets of diameter $10 \mathrm{~mm}$, thickness- $2 \mathrm{~mm}$ of this well dried powder were prepared. These pellets were put in a silica crucible and slowly heated until temperature reaches $850^{\circ} \mathrm{C}$. Holding at that temperature for 4 hours to complete the solid state sintering process and the organic binder to burnout [13-15. These final sintered pellets were cooled and polished and silver paste was applied to meet the requirement for electrical measurement.

\section{Experimental Details:}

The structural analysis of the complex perovskite for pure and Calcium modified Lead Titanate (PCT) system for $5,10,15,20 \& 25 \mathrm{~mol} \%$ have been performed by X-ray powder diffraction method, on X-Ray Diffraco meter (D-8 Advance Bruker axs) over a wide range of Bragg angles $\left(20^{\circ} \leq 2 \theta \leq 80^{\circ}\right)$ at room temperature using a filtered radiations $(\lambda=1.5406 \AA)$ was used. It is clear from X-ray diffraction pattern of pure and Calcium modified Lead Titanate as shown in fig.1-4 that there are no traces of any other compound and the line width indicate the product were homogeneous. From the following formula theoretical density for each sample is calculated,

$$
\mathrm{D}_{\mathrm{th}}=\left(\mathrm{M} . \mathrm{W} . \times 10^{24}\right) /\left(6.023 \times 10^{23} \times \mathrm{V}_{\mathrm{p}}\right)
$$

Where Dth is the theoretical density, M.W. is the molecular weight and $\mathrm{V}_{\mathrm{p}}$ is the volume of the unit cell calculated from X-ray data. The molar volume $\mathrm{V}_{\mathrm{m}}$ of the samples was calculated using the relation [16],

$$
\mathrm{V}_{\mathrm{m}}=\mathrm{M} / \rho
$$

Where $\mathrm{M}$ is the molecular weight and $\{\rho\}$ is the material density. The atomic concentration $\mathrm{N}(\mathrm{cm})^{-3}$, was calculated using the relation,

$$
N=\rho \times N_{A} / M .
$$

Where $\mathrm{N}_{\mathrm{A}}$ is the Avogadro's number,

The SEM of the samples was done on JEOL 6360A Analytical Scanning Electron Microscope. For the measurement of dc electrical conductivity the pellets were polished and silver pasts was applied and specially made pellet holder and silver electrodes were used.

\section{Result and discussions:}

The observed X-ray diffraction pattern of Calcium modified Lead Titanate is presented in fig.1-4 shows well resolved peaks. The values of full width at half maximum intensity indicate that the polycrystalline has a homogeneous perovskite structure. All the peaks were indexed with great care and lattice parameter ' $\mathrm{d}$ ' was calculated by using hkl values. The present data and published data are in excellent agreement and are listed in table no.1[17].The XRD study also shows that with the increase of Calcium concentration the lattice constant ' $c$ ' decreases while that of ' $a$ ' increases $[18,19]$. These results attribute that the $\mathrm{Ca}$ ions occupying $\mathrm{Pb}$ ions site with smaller ionic radius. The reduced c/a ratio suggests that the sample have perovskite phase with tetragonal structure with improved mechanical stability [20,21]. But the tetragonality decreases with increase of the $\mathrm{Ca}$ content that is different phases occur which depend on composition. It is also clear from table no.2 that material density and theoretical density are in good agreement. The density of Calcium modified Lead Titanate

\begin{tabular}{|c|c|c|c|c|c|c|c|c|c|c|c|c|c|}
\hline hkl & 001 & 100 & 101 & 110 & 111 & 002 & 200 & 102 & 201 & 210 & 112 & 211 & 202 \\
\hline Publishe & 4.1 & 3.89 & 2.84 & 2.84 & 2.2 & 2.0 & 1.9 & 1.8 & 1.76 & 1.7 & 1.6 & 1.6 & 1.4 \\
\hline $\begin{array}{l}\text { d data } \\
(\mathrm{d} \AA)\end{array}$ & 50 & 9 & 2 & 2 & 97 & 76 & 50 & 33 & 5 & 44 & 58 & 07 & 21 \\
\hline Present & 4.1 & 3.89 & 2.83 & 2.76 & 2.2 & 2.0 & 1.9 & 1.8 & 1.76 & 1.7 & 1.6 & 1.6 & 1.4 \\
\hline $\begin{array}{l}\text { data } \\
(\mathrm{d} \AA)\end{array}$ & 49 & 7 & 8 & 1 & 96 & 74 & 54 & 33 & 7 & 45 & 57 & 09 & 20 \\
\hline
\end{tabular}
sample is decreasing as Calcium contents are increasing. Which was expected as molecular mass of Lead is more than molecular mass of Calcium.

Table no. 1. h,k,l and d values from X-ray diffraction data. 


\begin{tabular}{lllllll}
\hline System & $6\left(\mathrm{~g} / \mathrm{cm}^{2}\right)$ & $\mathrm{D}_{\mathrm{Th}}\left(\mathrm{g} / \mathrm{cm}^{2}\right)$ & $V_{\mathrm{m}}(\mathrm{cm} / \mathrm{mal})$ & $V_{p}\left(\mathrm{~A}^{\circ}\right)^{2}$ & $\mathrm{c} / \mathrm{a}$ & $\mathrm{N} \times 10^{22}\left(\mathrm{~cm} \mathrm{~m}^{-2}\right)$ \\
\hline PT & 7.794 & 7.9708 & 38.879 & 63.121 & 1.0641 & 1.5449 \\
PCT1 & 7.921 & 8.1614 & 38.61 & 62.216 & 1.0622 & 1.5599 \\
PCT2 & 7.901 & 8.102 & 39.09 & 63.302 & 1.0510 & 1.5422 \\
PCT3 & 8.117 & 7.8593 & 38.3684 & 65.672 & $-\cdots$ & 1.5697 \\
\hline
\end{tabular}

The SEM of Calcium modified Lead Titanate shows that the uniform distribution of densely packed fine grains over the entire surface for a sample less Calcium content as shown in figures 5-8. As Calcium content is increased a typical characteristics of exaggerated grain growth, a duplex microstructure is observed. A slight Calcium excess composition forms a eutectic liquid ubiquitous impurity. In this respect the appearance of large grain suggests that Calcium doping decreases the eutectic temperature. As the liquid phase has high mobility and therefore it penetrates grain boundaries and exaggerated grain growth might have taken place. Further increases of Calcium content, the microstructure of specimen are almost identical as that of less Calcium content. No further grain growth but density slightly increases to critical value. This microstructural change has direct influence on dielectric properties. The average grain size of the sample determined by using Contrell's method was found to be in the range of $1-2 \mu \mathrm{m}[22]$. The microstructural analysis showed that as the $\mathrm{Ca}$ concentration increases, grain size first increases from $1.04 \mu \mathrm{m}$ to $1.52 \mu \mathrm{m}$ for $5 \mathrm{~mol} \%$ to $10 \mathrm{~mol} \%$ followed by the decrease up to $0.99 \mu \mathrm{m}$ for $15 \mathrm{~mol} \%$ [23-25]. This may be due to solubility limit.

The dc conductivity measurement was conducted for pure and Calcium modified Lead Titanate by two probe method using specially made pellet holder and silver electrode. The plot of $\ln \sigma_{\mathrm{dc}}(\mathrm{m})^{-1}$ for Calcium modified Lead Titanate as a function of 1000/T. This presentation enables us to evaluate activation energy $E_{a}$ using the well known Arrehenius formula

$$
\sigma_{\mathrm{dc}}(\mathrm{T})=\sigma_{0} \exp \left(-\mathrm{E}_{\mathrm{a}} / \mathrm{K}_{\mathrm{B}} \mathrm{T}\right)
$$

Where $\sigma_{0}$ is the pre- exponential factor, $K_{B}$ the Boltzmann constant, $T$ absolute temperature and $E_{a}$ is the activation energy.
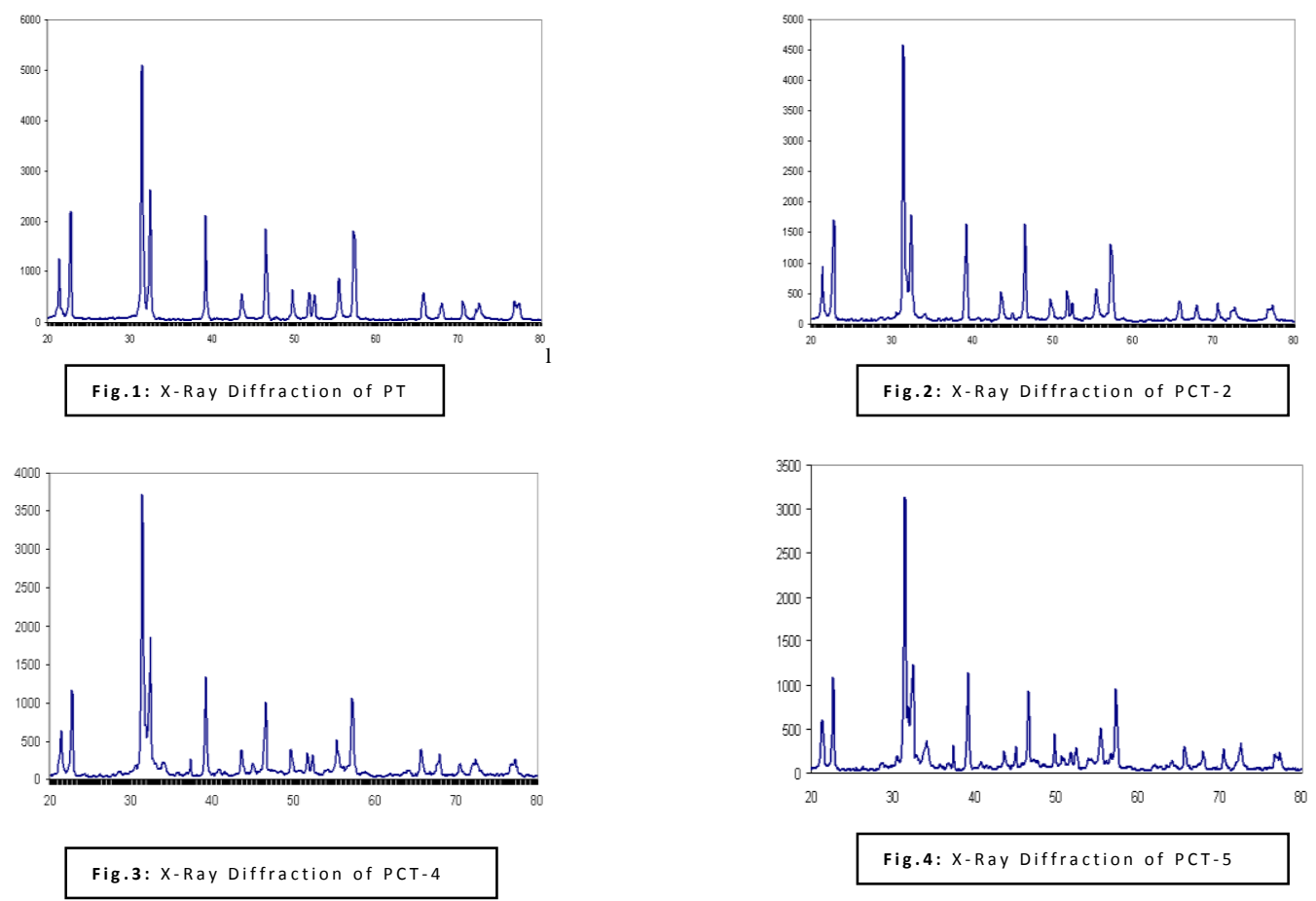


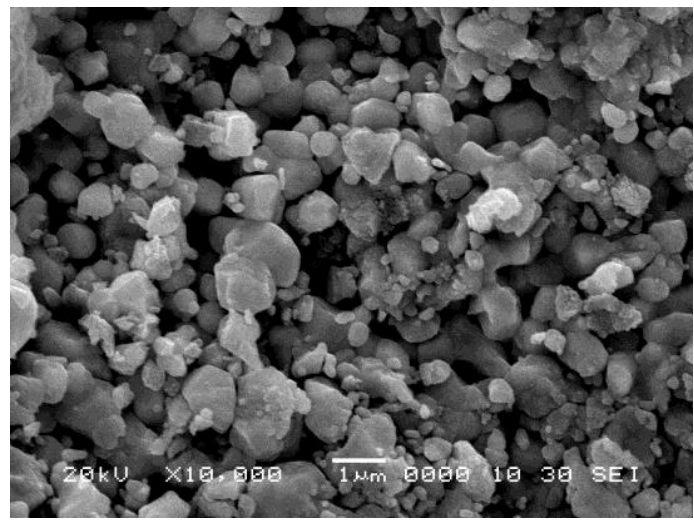

Fig 5: SEM image of PCT-1

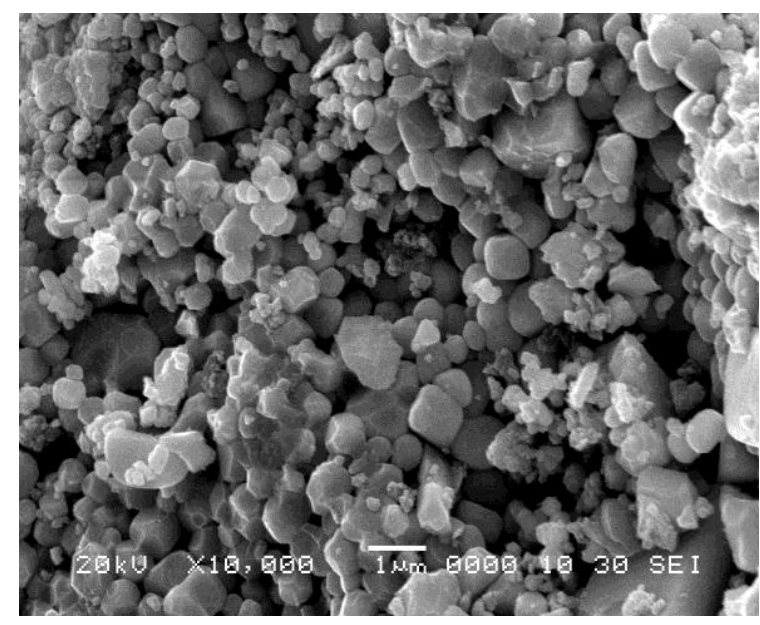

Fig 7: SEM image of PCT-3

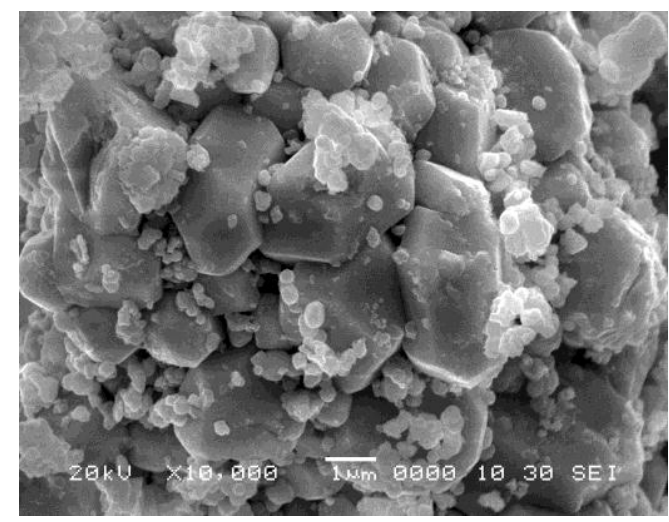

Fig6: SEM image of PCT-2

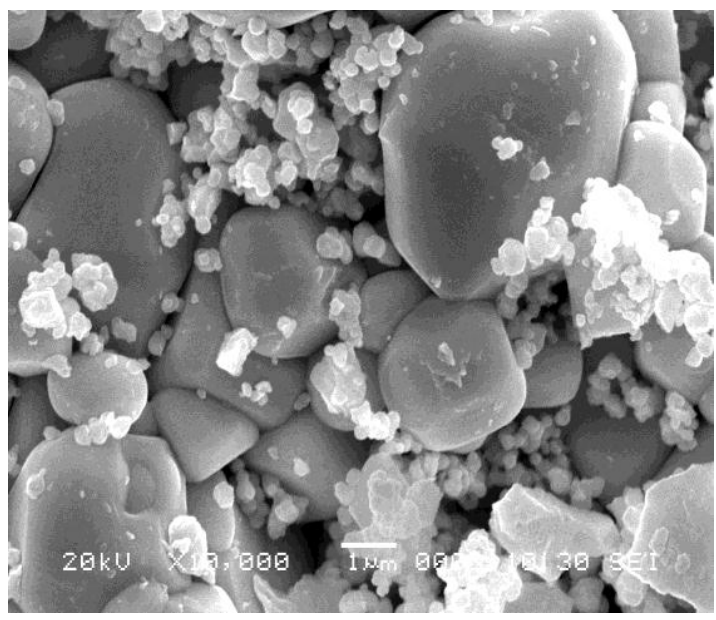

Fig 8: SEM image of PCT-4

These plots shows that there is no change in dc conductivity up to a certain temperature after that there is a sudden increase in dc conductivity value. This gives change of phase. The following figure shows that there is no continuous linear increase with temperature [26-27]. It has been observed that dc conductivity suddenly increases after a certain value in all the cases with respect to temperature. The following table gives the conductivity of the doped samples along with transition temperature. The transition temperature decreases with increase of Calcium concentration [28-29]. It is observed that the critical transition temperature is compositional dependent. Therefore behaviour of Calcium modified Lead Titanate is still complex.

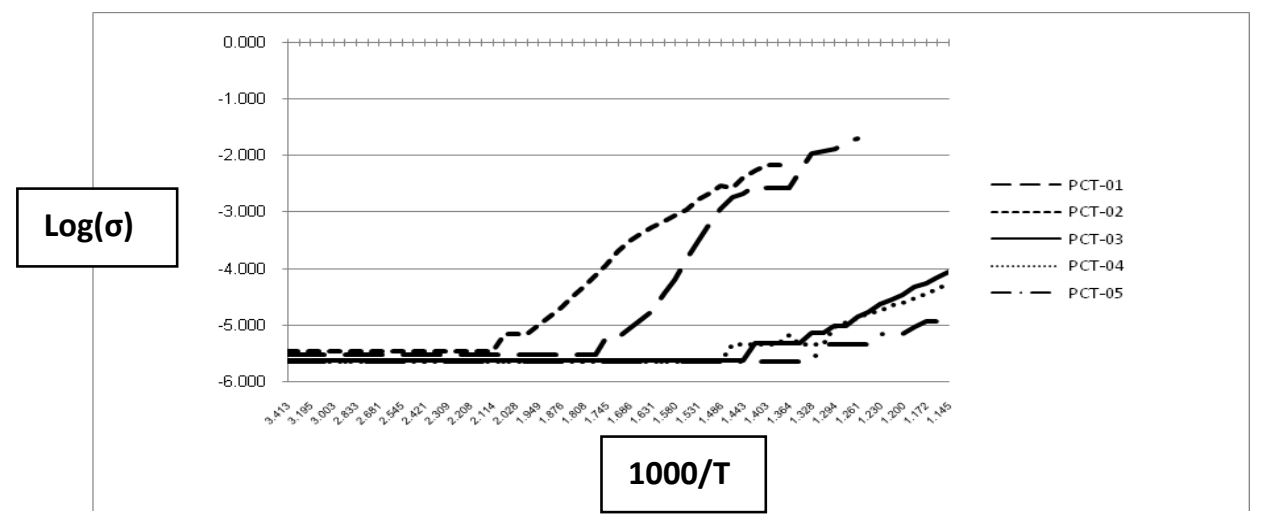

Fig No. 9 : d.c conductivity curve for Calcium modified Lead Titanate 


\begin{tabular}{|l|c|c|}
\hline \multicolumn{1}{|c|}{ Sample } & DC Conductivity (S) & Curie Temperature (K) \\
\hline PCT-1 $(5 \mathrm{~mol} \%)$ & $5.93145 \times 10^{-6}$ & 300 \\
\hline PCT-2 $(10 \mathrm{~mol} \%)$ & $6.94505 \times 10^{-6}$ & 210 \\
\hline PCT-3 $(15 \mathrm{~mol} \%)$ & $4.73946 \times 10^{-6}$ & 430 \\
\hline PCT-4 $(20 \mathrm{~mol} \%)$ & $4.58698 \times 10^{-6}$ & 410 \\
\hline PCT $-5(25 \mathrm{~mol} \%)$ & $4.57100 \times 10^{-6}$ & 490 \\
\hline
\end{tabular}

Table no.3: Curie temperature for Calcium modified Lead Titanate.

\section{Conclusion:}

Calcium modified Lead Titanate ceramics prepared by mechanical mixing of their oxides in molar proportion are completely crystallised into perovskite phase. The X-ray diffraction analysis shows tetragonality, polycrystalline ceramic with c/a ratio of pure Lead Titanate - and decreases with increasing mole percent of Calcium and disappears at about 20 mole percent of Calcium. The calculated lattice parameters and volume of the unit cell decreases by increasing Calcium content. The effect of Calcium dopant on Lead Titanate appears clearly on dc conductivity values at room temperature as well as around phase transition which are thermally activated. Addition of Calcium has lowered the curie temperature of modified Lead Titanate sample. The micro structural analysis showed that as the Ca concentration increases, grain size first increases up to $10 \mathrm{~mol} \%$ followed by the decreases. This may be due to solubility limit.

\section{References:}

[1]. J. Valasek, Phys. Rev. 17 (1921) 475.

[2]. A.Ahmed, K.Besso, S.Chehab,T.A.Wheat. J. Mater.Sci.25(1990),5289-5302.

[3]. A.J. Moulson and J.M. Herbert, Electro ceramics, Chapman and Hall, 1990, U.K

[4]. Pontes F.M, Pontes D.S.L,Leite E.R \& Longo E ,J.Appl.Phys 94 (2003).7256.

[5]. Chauhan A K S,Gupta V \& Sreenivas K,Mater Sci Engg,B 130(2006) 81.

[6]. T. Yamamoto, M.Saho, K. Okazaki, and E. Goo, Jap. J. Appl. Phys., 26-2, 57 (1987)

[7]. K. M. Rittenmyer, and R. Y. Ting, Ferroelectrics, 110, 171 (1990)

[8]. K. Takeuchi, D. Damjanovic, T. R. Guraraja, S. L. Jang, and L. E. Cross, Proc. 1986 IEEE Symp. Appl. Ferroelectrics, 402 (1986)

[9]. Y. Yamashita, K. Yokoyama, H. Honda, and T. Takahashi, Jap. J. Appl. Phys., 20-4, 183 (1981).

[10]. Goldschmidt V W, J Math Naturwide Klass 2(1926) 97.

[11]. Megav H D,Trans Faraday Soc.A 142 (1946)224.

[12]. "Butwar Ceramic Binder Applications Technical Bulletin" Solutia Inc.

[13]. James S. Reed, "Principles of Ceramic Processing," Chapter 29, Second Edition, John Wiley \& Sons, New York (1995).

[14]. I. Udea Jpn J. Appl. Phys.11(1972)450.

[15]. L.Eyarud, P.Eyarud,F. Gonnard\& M.Troccaz,Ferroelectrics 341(1981)133.

[16]. Sindhu S,Sanghai S,Agarwal A,Seth V P\& Kishor N J,Mater.Chem.Phys.90(2005)83.

[17]. S. Chopra et al./ Applied Surface Science 230 (2004) 207-210.

[18]. B. Jaffe, W.R Cook and Jr. H. Jaffe, Piezoelectric Ceramics, Academic Press, London (1971)p119.

[19]. Pontes F.M, Pontes D.S.L,Leite E.R \& Longo E, Santos E M \& Mergathao S J.Appl.Phys 91 (2002)6650.

[20]. J.Tartaj, C.Moure ,L Lascano, P Duran.Mater.Res.Bulletin 36(2001)2301-2310.

[21]. E Yanaka, H Watenabe, N Kimura, N Kanaya,H Ohkuma.J.Vac.Sci.Technol Ab(1988)052921.

[22]. A Contrell, An Introduction to Metallurgy (Arnold, London, 1975)p 173.

[23]. J.R.R. Siqueira et al/ceramics International 33(2007)937-941.

[24]. Singh H P \& Gupta D 1986 Indian J.Pure \& Appl.Phys. vol.24 D444.

[25]. S Chewastn, S J Milno. J. Mater. Sci.32,575,1997.

[26]. S Hinano,T Yoga, K Kikuta, Y Araki, M Saitoh, S Ogasahava. J. Am. Ceram.Soc.75,2785,1992.

[27]. Navin Chand and Archana Nigrawal Advanced Materails and Processes, Research Institute Habibganj, India pg. 666 - 667.

[28]. S. Ganesa Moorthy, F. Joseph Kumar, S. Balakumar and C. Subramanian page no. S1214, Journal of Korean Phy. Soc. Vol 32. Feb. 1998

[29]. N M El Mallah, Indian J. Pure \& Appl. Phys. Vol.49 Nov.2011 p 769-775. 